\title{
Commentary
}

\section{How Is CDC Funded to Respond to Public Health Emergencies? Federal Appropriations and Budget Execution Process for Non-Financial Experts}

Leah S. Fischer, Scott Santibanez, Greg Jones, Bethany Anderson, and Toby Merlin

The federal budgeting process affects a wide range of people who work in public health, including those who work for government at local, state, and federal levels; those who work with government; those who operate government-funded programs; and those who receive program services. However, many people who are affected by the federal budget are not aware of or do not understand how it is appropriated or executed. This commentary is intended to give non-financial experts an overview of the federal budget process to address public health emergencies. Using CDC as an example, we provide: (1) a brief overview of the annual budget formulation and appropriation process; (2) a description of execution and implementation of the federal budget; and (3) an overview of emergency supplemental appropriations, using as examples the 2009 H1N1 influenza pandemic, the 2014-15 Ebola outbreak, and the 2016 Zika epidemic. Public health emergencies require rapid coordinated responses among Congress, government agencies, partners, and sometimes foreign, state, and local governments. It is important to have an understanding of the appropriation process, including supplemental appropriations that might come into play during public health emergencies, as well as the constraints under which Congress and federal agencies operate throughout the federal budget formulation process and execution.

Keywords: Public health preparedness/response, Legislative issues, Legal aspects, Epidemic management/response

$F_{c}^{a}$ OR OVER HALF a CENTURY, the Centers for Disease Control and Prevention (CDC) has led efforts to protect the public's health in the United States and abroad. Public health emergencies such as the $2009 \mathrm{H} 1 \mathrm{~N} 1$ influenza pandemic and 2014-15 Ebola outbreak require rapid action and present special challenges in funding. The process of establishing and executing budgets was designed to assure responsibility for and accountability of federal funds. However, this process can be challenged by a rapidly evolving emergency. Understanding the federal budget

Leah S. Fischer, PhD, is a Health Scientist; Scott Santibanez, MD, is Associate Director for Science; Greg Jones, MPA, is Senior Advisor for Program Integration; and Toby Merlin, MD, is Director; all in the Division of Preparedness and Emerging Infections, Centers for Disease Control and Prevention, Atlanta, Georgia. Bethany Anderson, MS, is Senior Public Health Advisor, Office of Appropriations, Centers for Disease Control and Prevention, Atlanta. The contents of this work are solely the responsibility of the authors and do not necessarily represent the official views of the CDC. 
process is important, because it opens the way for coordination of responses during public health emergencies. Unfortunately, for many people the federal budget and appropriations processes are confusing. This commentary is intended to give non-financial experts an overview of the federal budget process to address public health emergencies. Using CDC as an example, we provide: (1) a brief overview of the annual budget formulation and appropriation process; (2) a description of execution and implementation of the federal budget; and (3) an overview of emergency supplemental appropriations.

\section{Overview of the Federal Budget PROCESS}

\section{Federal Budget Formulation and Appropriations}

The Office of Management and Budget (OMB), an office that assists the president in budgetary responsibilities of the executive branch of the US government, oversees the federal government's annual budget request to Congress. Formulation of the president's budget proposal begins with federal agency budget requests. Departments and agencies across the federal government prepare detailed estimates of expenditures for personnel, contracts, grants, travel, supplies, and equipment and propose changes to funding levels. These budget requests are reviewed and revised with guidance from $\mathrm{OMB}$, which then recommends budget levels to the president. From beginning to end, formulation of the president's budget request takes several months and involves much discussion, planning, and decision making. When this process is complete, the president submits the annual budget request to Congress, between the first Monday in January and the first Monday in February, as mandated by the current federal budget law (31 U.S.C. $\S 1105(\mathrm{a})$ ). ${ }^{1}$

The president's budget request reflects the administration's positions on ongoing programs and various new initiatives and does not have binding authority on Congress. Public health appropriations are influenced by a number of factors, including the administration's goals and priorities, constituent interests, current pressing public health concerns, and the political environment. Ultimately, Congress decides the amount of funding appropriated to different agencies, including the purpose, the length of time the funds are available to be spent, and other parameters. When the appropriations process works as designed, Congress passes appropriations bills by October 1; the president signs the bills to start the federal fiscal year. Unfortunately, the funding process does not always proceed as expected. If Congress is unable to reach agreement on the individual appropriations bills, they may (1) combine separate appropriations bills into an omnibus spending package, which allows for a greater range of negotiation and reduces the likelihood of a presidential veto; or (2) enact short-term spending bills, known as continuing resolutions (CRs); often a combination of approaches is used. Continuing resolutions typically maintain the previous year's funding levels, although they may include changes to policy and funding levels. A government shutdown occurs when separate or consolidated/ omnibus appropriations bills are not passed and signed on time and there is no continuing resolution.

\section{Annual HHS Appropriations and Budget Execution}

Appropriations for most of the Department of Health and Human Services (HHS) are grouped with the Departments of Labor and Education and related agencies in the "LaborHealth and Human Services-Education and Related Agencies" appropriations bill. ${ }^{* 1}$ In HHS, entities such as CDC, the National Institutes for Health, and the Centers for Medicare and Medicaid Services are known as operating divisions (OPDIVs). A number of funding lines are associated with HHS, a subset of which are designated for CDC.

Executive agencies like HHS submit a formal request to $\mathrm{OMB}$ to access appropriated funds. OMB determines how the appropriations will be divided and distributed within the parameters set by Congress. In addition to distributing appropriations to executive agencies, $\mathrm{OMB}$ advises agencies that particular funds are to be used for congressionally specified purposes, including explicit directives, intent, and other important guidance on Congressional preferences. ${ }^{2}$

Once OMB distributes appropriated funds, executive agencies such as HHS have the discretion to conduct activities within the purpose of the appropriation and in alignment with congressional directives. CDC receives its funding from Congress through separate accounts that correspond approximately to CDC's centers, institutes, and offices. These accounts are further subdivided into specific programs, projects, and activities. CDC uses the funds to support staff, to acquire goods and services such as office and laboratory equipment and supplies, and for travel. A substantial portion of CDC's annual budget goes out to partners such as state and local health departments and universities via grants, cooperative agreements, and contracts (see sidebar). ${ }^{3}$

*The Labor, Health and Human Services (LHHS) funding bill includes funding for programs in the Departments of Labor, Health and Human Services, and Education and other related agencies, such as the Corporation for National and Community Service, the Corporation for Public Broadcasting, the National Labor Relations Board, and the Social Security Administration. In HHS, the legislation provides funding for the Institutes of Health, CDC, the Substance Abuse and Mental Health Administration, the Health Resources and Services Administration, the Centers for Medicare and Medicaid Services, the Administration for Children and Families, and the Administration for Community Living. 
Cooperative Agreements, Grants, and Contracts: Which Mechanism to Use?

The decision about which depends on the type of public health activity to be accomplished.

- Cooperative agreements are a form of grant and are used when CDC has substantial involvement in the activities being funded.

- Grants are used when CDC has no need for substantial involvement beyond normal oversight and monitoring over the course of the grant cycle. Grants are flexible around scope of work, budget, and other changes; diligent efforts are used in completing research and the delivery of results; payment is awarded in annual lump sum; generally, annual reporting requirements.

- Contracts are used to purchase goods and services such as supplies, vaccines, information technology (IT), and equipment for CDC use. Emphasis is placed on delivery of results, product, or performance, and payment is based on deliverables and milestones.

\section{Overview of Emergency Supplemental ApPropriations}

\section{CDC's Response to Public Health Emergencies}

Infectious disease outbreaks that require CDC's attention and resources occur frequently. Often, CDC must respond to public health emergencies within their existing annual appropriation. As mentioned above, CDC's annual appropriations include funding for staff, travel, contractual services, grants, office and laboratory equipment, and supplies that initially support, among other things, the agency's ability to protect the public's health against emerging public health threats. These funds additionally enable CDC to maintain the capability and expertise to plan for and respond to infectious disease outbreaks and public health emergencies. It is a core function of CDC to always be prepared and able to respond, and CDC responds to small-scale emergencies and requests for assistance every day.

When larger public health emergencies arise, CDC may assign staff to emergency operations, logistics and coordination, and scientific and technical roles such as epidemiologists and laboratory specialists. These staff work either in CDC's Emergency Operations Center or are deployed to the location(s) of the public health event. Up to a point, CDC's annual appropriations cover the costs associated with a public health response. When a public health emergency escalates and requires resources beyond CDC's annual budget, but Congress has not approved emergency appropriations, HHS and CDC have some limited flexibility to redirect funds. This can require the HHS Secretary to notify Congress of a budget transfer, meaning that funds are moved from one appropriations account to another, or a reprogramming, which moves funds within one account but to a different program, project, or activity. If an emergency appropriation is ultimately passed, the legislation can include the ability for HHS and CDC to replenish the funds that were redirected. Nonetheless, when the needs of a public health emergency expand beyond CDC's base capacity to respond, supplemental funding is required to implement an effective response. ${ }^{4}$

\section{Public Health Supplemental (Emergency) Funding}

In addition to regular appropriations bills and continuing resolutions, Congress can pass supplemental appropriations. ${ }^{5}$ This might occur when the need for funds is too urgent to be postponed until the next regular annual appropriations act, such as during a public health emergency. Funding can be appropriated as "emergency" or "supplemental" funding by Congress.

Public health emergencies may be officially declared by the US government (eg, the Secretary of HHS) or not. A formal declaration may be based on a domestic situation, or it can follow a declaration by the World Health Organization of a public health emergency of international concern (PHEIC). Upon recognition of an emergency situation, $\mathrm{OMB}$ requires the involved federal agencies to submit a justification that details when funding is needed and estimated expenses. Once the justification is finalized, $\mathrm{OMB}$ submits the request to Congress and coordinates between Congress and HHS to address any questions that arise. Typically, agency directors and senior staff are called on to testify before congressional committees when supplemental appropriations are considered. During this time, agencies continue to plan and prepare so that they can rapidly implement the plan should Congress decide to appropriate supplemental funds.

Congress has provided funding for public health emergencies in several recent instances. For example, in June 2009, President Obama signed Public Law 111-32, in which Congress appropriated approximately $\$ 7.65$ billion to HHS for the 2009 H1N1 influenza pandemic, much of which was designated for support to state and local health departments and other US partners. ${ }^{6}$ In December 2014, Congress appropriated $\$ 5.4$ billion $^{7}$ to respond to the 2014-15 Ebola outbreak. From this emergency appropriation, $\$ 1.77$ billion was appropriated to CDC, of which approximately $\$ 576$ million was for the domestic response. ${ }^{8}$ In September 2016, CDC received approximately $\$ 350$ million in supplemental appropriations to respond to the Zika virus. ${ }^{9}$

Most recently, lawmakers have considered the possibility of establishing a public health emergency fund "to provide assistance for immediate Federal, State, local, or international response needs with respect to any public health emergency" and "for activities determined appropriate by 
the Secretary to improve preparedness and response to protect human health for all populations in any public health emergency."10

\section{After an Emergency or Supplemental Appropriation}

When supplemental or emergency funding is appropriated (often during a public health emergency), CDC may use the funds only within the scope of the purpose for which the funds were intended. For example, if the funds were appropriated in response to a public health emergency (such as an outbreak of an infectious disease or a hurricane), CDC may use funds to provide for a surge in response, laboratory, and technical staff; to acquire goods and services, such as travel, office and laboratory equipment, and supplies; or to provide grants, cooperative agreements, or contracts in support of CDC's efforts (see sidebar).

\section{CDC's Epidemiology and Laboratory for Infectious Diseases (ELC) Cooperative Agreement}

CDC funds state and local health department programs aimed at preparedness and response to public health emergencies and infectious diseases. For example, Congress appropriates money through HHS for CDC's Epidemiology and Laboratory for Infectious Diseases (ELC) Cooperative Agreement. CDC funds all 50 state health departments, 6 local health departments (Chicago, the District of Columbia, Houston, Los Angeles County, New York City, and Philadelphia), and 8 territories or US affiliates to detect, prevent, and respond to infectious disease outbreaks. In 2015, ELC distributed nearly $\$ 200$ million, including approximately $\$ 100$ million specifically to support state and local Ebola epidemiology and laboratory activities targeting prevention.

In contrast to the budget execution process for annual appropriations, supplemental appropriations may allow the agency greater flexibility in how funds are spent to tailor the response to address the specific public health emergency. Through supplemental funding during the Ebola response, thousands of CDC staff provided logistics, staffing, communication, analytics, management, and other support functions. In 2014-15, there were 2,471 CDC staff deployments to West Africa, and 24,665 West African health workers were trained by CDC. In the United States, CDC and partners conducted live training in New York City, Los Angeles, and Philadelphia, reaching more than 6,500 healthcare staff in person and more than 20,000 via webcast. CDC worked with airlines, airports, ministries of health, and other partners in West Africa to identify trav- elers who may have had Ebola symptoms or exposure, to prevent them from leaving a country until it could be confirmed that they were not sick and not at risk of spreading Ebola. ${ }^{11}$

\section{CONCLUSION}

We have described how federal funds provide the resources that CDC uses to prepare for and respond to public health emergencies, but this is a simplified conceptual overview of the appropriations process, intended to inform program managers and public health practitioners. It may not fully represent the complexities of the process or address the full legal implications of the appropriations process. We conclude with several key points:

First, protecting the American people during a large emergency response requires substantial personnel, equipment, and resources. The past decade has demonstrated this during the $2009 \mathrm{H} 1 \mathrm{~N} 1$ influenza pandemic and the 201415 Ebola outbreak.

Second, a variety of staff have essential responsibilities in the federal budgeting process. Federal workers play an important role in budget formulation and execution-from the analyst responding to requests from $\mathrm{OMB}$ and revising budget estimates to guide development of the president's budget, to frontline public health workers involved in emergency response who identify travelers who may have been exposed to Ebola. Recipients of federal funds through grants and cooperative agreements also have an important role and should understand the congressional intent behind the funding they receive and the rationale behind any congressionally mandated reporting processes. Grant and cooperative agreement administration involves good stewardship and is designed, appropriately, to ensure accountability of expenditure of federal funds.

Third, it would be beneficial to recognize the importance of the appropriation process and the constraints under which Congress and federal agencies operate. Public health emergencies require rapid coordinated responses among Congress, government agencies, partners, and sometimes foreign, state, and local governments. The processes described can be strained by a rapidly evolving emergency, when the need for funds outpaces availability. We hope that improved understanding of federal appropriations and budget execution processes will open the way for greater coordination in preparing for and responding to public health emergencies.

\section{REFERENCES}

1. Tollestrup J. The Congressional Appropriations Process: An Introduction. CRS Report 97-684, February 23, 2012. https://www.fas.org/sgp/crs/misc/97-684.pdf. Accessed April 5, 2016. 
2. Christensen M. The Executive Budget Process: An Overview. CRS Report R42633. https://www.fas.org/sgp/crs/misc/ R42633.pdf. Accessed April 5, 2016.

3. Centers for Disease Control and Prevention. Funding: life cycle overview. CDC website. Updated September 29, 2015. http://www.cdc.gov/grants/lifecycleoverview/index.html. Accessed April 5, 2016.

4. United States Government Accountability Office. A Glossary of Terms Used in the Federal Budget Process (GAO-05-734SP). September 2005. http://www.gao.gov/new.items/d05734sp. pdf. Accessed April 5, 2016.

5. Office of Management and Budget. Circular No. A-11. Preparation, Submission, and Execution of the Budget. https:// obamawhitehouse.archives.gov/sites/default/files/omb/assets/ a11_current_year/a11_2016.pdf. Accessed April 18, 2017.

6. The White House, Office of the Press Secretary. Letter from the President regarding H1N1. July 16, 2009. https://obamawhite house.archives.gov/the-press-office/letter-president-regardingh1n1. Accessed April 18, 2017.

7. Consolidated and Further Continuing Appropriations Act, 2015 (H.R. 83) (Public Law 113-235).

8. Centers for Disease Control and Prevention. FY 2015-2019 Emergency Funding. Ebola Domestic Response-\$576M. http://www.cdc.gov/budget/documents/ebola/fy-2015-2019ebola-factsheet-domestic.pdf. Accessed April 18, 2017.
9. Continuing Appropriations and Military Construction, Veterans Affairs, and Related Agencies Appropriations Act, 2017, and Zika Response and Preparedness Act, 2016 (H.R. 5325) (Public Law 114-223).

10. Congressional Research Service. S. 196: Public Health Emergency Response and Accountability Act. https://www.govtrack. us/congress/bills/115/s196/text. Accessed February 27, 2017.

11. Centers for Disease Control and Prevention. The Road to Zero: CDC's Response to the West African Ebola Epidemic 20142015. http://www.cdc.gov/about/pdf/ebola/ebola-photobook070915.pdf. Accessed April 18, 2017.

Manuscript received January 30, 2017;

revision returned February 23, 2017;

accepted for publication March 1, 2017.

Address correspondence to: Leah S. Fischer, PhD, MBA

Health Scientist

Division of Preparedness and Emerging Infections National Center for Emerging \& Zoonotic Infectious Diseases 1600 Clifton Rd. NE Centers for Disease Control and Prevention Atlanta, GA 30329-4018

Email: 1sfischer@cdc.gov 